\title{
Participants Attrition in a Longitudinal Study: The Malaysian Cohort Study Experience
}

\author{
Noraidatulakma Abdullah (D), Mohd Arman Kamaruddin, Ying-Xian Goh ${ }^{(}$, Raihannah Othman, Andri Dauni, \\ Nazihah Abd Jalal, Nurul Ain Mhd Yusuf, Salywana A. Kamat, Nor Hazlinawati Basri and Rahman Jamal *
}

check for

updates

Citation: Abdullah, N.; Kamaruddin, M.A.; Goh, Y.-X.; Othman, R.; Dauni, A.; Jalal, N.A.; Yusuf, N.A.M.; Kamat, S.A.; Basri, N.H.; Jamal, R.

Participants Attrition in a

Longitudinal Study: The Malaysian Cohort Study Experience. Int. J Environ. Res. Public Health 2021, 18 7216. https://doi.org/10.3390/ ijerph18147216

Academic Editors: Paul B. Tchounwou and André Esser

Received: 17 May 2021

Accepted: 29 June 2021

Published: 6 July 2021

Publisher's Note: MDPI stays neutral with regard to jurisdictional claims in published maps and institutional affiliations.

Copyright: (c) 2021 by the authors. Licensee MDPI, Basel, Switzerland. This article is an open access article distributed under the terms and conditions of the Creative Commons Attribution (CC BY) license (https:// creativecommons.org/licenses/by/ $4.0 /)$.
UKM Medical Molecular Biology Institute (UMBI), Universiti Kebangsaan Malaysia, Kuala Lumpur 56000, Malaysia; noraidatulakma.abdullah@ppukm.ukm.edu.my (N.A.); arman@ppukm.ukm.edu.my (M.A.K.); yingxian@ukm.edu.my (Y.-X.G.); raihannah@ukm.edu.my (R.O.); andri@ppukm.ukm.edu.my (A.D.); nazihah.aj@ukm.edu.my (N.A.J.); ainmdy@ukm.edu.my (N.A.M.Y.); salywana@gmail.com (S.A.K.); lynnebasri@gmail.com (N.H.B.)

* Correspondence: rahmanj@ppukm.ukm.edu.my; Tel.: +60-9145-9000

Abstract: The attrition rate of longitudinal study participation remains a challenge. To date, the Malaysian Cohort (TMC) study follow-up rate was only $42.7 \%$. This study objective is to identify the cause of attrition among TMC participants and the measures to curb it. A total of 19,343 TMC participants from Kuala Lumpur and Selangor that was due for follow-up were studied. The two most common attrition reasons are undergoing medical treatment at another government or private health center $(7.0 \%)$ and loss of interest in participating in the TMC project $(5.1 \%)$. Those who were inclined to drop out were mostly Chinese, aged 50 years and above, unemployed, and had comorbidities during the baseline recruitment. We have also contacted 2183 participants for the home recruitment follow-up, and about $10.9 \%$ agreed to join. Home recruitment slightly improved the overall follow-up rate from $42.7 \%$ to $43.5 \%$ during the three-month study period.

Keywords: cohort retention; attrition; the Malaysian Cohort; follow-up methodology; Asian population

\section{Introduction}

The challenges in a cohort study include the relatively high cost due to the prospective nature of the study [1], the labor-intensive follow-up process [2], and the drop in the response during follow-up [3]. The retention of participants is a big challenge, especially when the cohort participants are from the general population instead of a defined group of people with common traits [1]. Although the ideal follow-up rate of $50 \%$ is considered adequate, while $60 \%$ is good and $70 \%$ is very good [4], these numbers are difficult to achieve. During follow-up, the attrition rate of participants is crucial, as it might introduce a certain form of selection bias to the overall cohort study $[5,6]$ and probably lead to the loss of statistical power in the analysis [7-9]. In addition, attrition can also be considered missing not at random (MNAR), which might influence the result of the analysis due to bias [10-13]. Since attrition could be a serious threat for longitudinal studies, previous studies have identified demographic and clinical characteristics associated with attrition. However, not all studies investigated the same factors, making it hard to summarize [14]. Some consistent findings related to attrition rate in longitudinal studies were aging, being a woman, fewer years of education, lower economic status, frailty, poor health, not having a family history of dementia, and cognitive impairment [14-20]. In addition, several neuropsychological tasks, such as having slower processing speed, less attentional flexibility, worse delayed verbal recall, and MRI markers, were associated with the attrition rate that might presumably be mediated by cognitive skills $[16,21,22]$.

The Malaysian Cohort (TMC) project is a large population-based cohort study that managed to recruit 106,527 participants over a period from the year 2006 until 2012 [23]. The objective was to follow-up with the participants quinquennially (every five years) 
using the re-survey approach, a follow-up phone call, and passive surveillance to capture any morbidity and mortality events. During the re-survey, participants needed to answer a questionnaire and undergo biophysical measurements similar to the baseline recruitment plus other tests. Blood and urine samples were also collected. They were also called by phone to verify any morbidity and mortality event using a standardized set of questions. For passive surveillance, we received the mortality notification including the cause of death details every six months from the National Registry Department of Malaysia.

TMC follow-up methods [23] included a biannual health diary for participants to fill out and return, biannual follow-up calls, and a comprehensive quinquennial follow-up to retain the participants. Regular reminders were conducted via post mail, phone call, short messaging service, WhatsApp, non-monetary incentives, and tracing via family members (who are also participants), friends, and employers $[3,24]$. Despite all of these efforts, the attrition rate of $57.3 \%$ was still a major challenge. Thus, this paper aims to identify the cause of attrition among TMC participants and the measures to curb it.

\section{Materials and Methods}

\subsection{Study Population}

The study samples were those residing in the states of Kuala Lumpur and Selangor, which consisted of 41,696 participants. The following participants were then excluded: (1) 17,799 participants who had been successfully followed-up (42.7\% follow-up rate), (2) 1458 participants (3.5\%) who had died after baseline recruitment and verified by the National Registry Department of Malaysia as of December 2018, and (3) 3096 participants that had already agreed and scheduled a follow-up. The final number of participants in this follow-up study was 19,343. Written informed consent (read and signed) was obtained from the subjects. The project has been approved by the research ethics committee of the Universiti Kebangsaan Malaysia (Project code: FF-205-2007), in accordance with the Declaration of Helsinki.

\subsection{Data Collection}

There were two phases of the study: (1) follow-up appointment calls via phone using a standardized questionnaire and (2) home follow-up. In the first phase of the study, the data collection was done using a standardized computerized questionnaire that was filled out by trained staff members. The questionnaires ask information regarding the participants' personal data, occupational history, self-reported medical history with medication, dietary habits, physical activity, and lifestyle histories, such as tobacco and alcohol use. Comorbidities, such as hypertension, hypercholesterolemia, diabetes mellitus, and obesity were measured using two methods: (1) self-reporting and (2) health assessment. For self-reported comorbidities, the participants were asked whether a medical doctor had diagnosed them with the disease and whether they had taken any medication for it. Among the diseases that were diagnosed through health assessment during the recruitment were hypertension (indicated by a blood pressure test was more than $140 / 90 \mathrm{mmHg}$ ), hypercholesterolemia (total cholesterol test was more than $5.2 \mathrm{mmol} / \mathrm{L}$ ), diabetes mellitus (fasting blood glucose test was more than $7 \mathrm{mmol} / \mathrm{L}$ ), and obesity (body mass index measurement was more than $30 \mathrm{kgm}^{-2}$ ). The participants were each called for at least three attempts via their mobile number, home landline, or office telephone number recorded in the database. Their responses were then recorded and categorized into 22 common responses. Based on that, we identified the reasons that could be possibly resolved by doing a home follow-up, which involved our staff collecting data and performing health assessments at the participant's residences. Among the 22 responses, participants with the following responses were selected for the home follow-up approach: (1) "The participant was uncertain to join for follow-up or made an ambiguous response"; (2) "The participant could not attend the follow-up due to work or just busy"; and (3) "The participant could not join due to transportation problems". These three categories were selected because they were interested in joining, but were set back by their commitment and transportation 
problems. Thus, TMC takes the initiative to go to them for home follow-up. The homefollow-up approach was conducted for three months, from March 2019 until May 2019.

\subsection{Preparation for Home Recruitment}

The home follow-up team consisted of three members, including a driver, a phlebotomist who was also the on-site lab technician, and an enumerator who also did the biophysical measurements. Two teams were used during the study period, and each team was scheduled to visit four to five participants daily. A prefilled informed consent form and a shortened version of the questionnaire were printed and brought to the homes. The questionnaire was also prefilled with the previous data for the relevant participant to be cross-validated and updated during the home follow-up. The biospecimen tubes were already pre-labeled with the participant's identification number (SID).

\subsection{Home Recruitment}

Anthropometric data (such as weight, height, and waist-hip circumference) were measured using a portable stadiometer (Harpenden, SERITEX, Wales, UK), a Seca weighing scale, and a Seca circumference measuring tape. Blood pressure measurements (both in the standing and sitting positions) were obtained using digital automatic blood pressure monitor (HEM-907, OMRON, Kyoto, Japan). The assessment was repeated three times, and the average value was recorded.

Blood and urine samples were collected using standard procedures. The blood-filled fluoride vacutainer was centrifuged on the spot and kept in a cool box immediately at $2-8{ }^{\circ} \mathrm{C}$ to prevent hemolysis. The samples were brought back to the laboratory at the main center for subsequent processing.

The questionnaire was administered via an interview and also recorded using a MP3 device. The whole interview session took about $15 \mathrm{~min}$ on average. The home follow-up process took an average of 35 to $40 \mathrm{~min}$, excluding travel time. The time spent was notably shorter than the follow-up at our main recruitment center, which usually takes around two hours. The biophysical measurements and questionnaire data were recorded into the online database at the main center.

\subsection{Statistical Analyses}

All statistical analyses were performed using the Statistical Package for the Social Sciences (SPSS version 22.0, IBM, Armonk, NY, USA). Chi-squared tests calculated differences in appointment status based on gender, ethnicity, age group, education level, working status, and comorbidities, and a $p$-value of $<0.05$ was considered statistically significant. Logistic regression using the likelihood ratio method was used to identify risk factors associated with attrition rate. Statistically significant risk factors identified in the uni-variable analysis $(p<0.05)$ were then included in the multivariable analysis. Odds ratios and their $95 \%$ confidence intervals were provided as estimates of the effect size, and the test was conducted at a 5\% level of significance.

\section{Results}

Participants' Responses and Reasons of Attrition

The participants' responses from the follow-up calls were described in Table 1. Out of 19,343 participants due for follow-up, $6.1 \%$ of calls were successful with participants agreeing to join; $0.2 \%$ had attended the follow up (44 people), $15.3 \%$ were unsuccessful due to participant's withdrawal, $0.1 \%$ had died, while another $78.3 \%$ needed to be contacted again. Those considered as a dropout were those who withdrew from the study. The most frequent reasons stated by the abovementioned participants were that they already underwent treatment at another government or private health center $(7.0 \%)$ and lost interest in participating in the TMC project $(5.1 \%)$. Although we updated our mortality data from the National Registry Department of Malaysia biannually, we missed the 19 deaths in between. 
Table 1. Follow-up appointment calls responses of TMC participants residing in the Kuala Lumpur and Selangor area, Malaysia, March through May $2019(\mathrm{~N}=19,343)$.

\begin{tabular}{|c|c|}
\hline Follow-Up Appointment Calls Responses & Frequency $(\%)$ \\
\hline Successful appointment call: & $1226(6.3)$ \\
\hline Participant agreed to come for follow-up & $1182(6.1)$ \\
\hline Participants informed that they had attend the follow-up & $44(0.2)$ \\
\hline Need to re-contact for an appointment via call or another platform: & $15,125(78.3)$ \\
\hline The telephone call was not answered & $4468(23.1)$ \\
\hline The participant was uncertain about coming/had an ambiguous response * & $4375(22.6)$ \\
\hline The telephone number was not in service & $2392(12.4)$ \\
\hline Wrong telephone number/changed to a different unknown number & $1140(5.9)$ \\
\hline The participant unable to come due to busy/working * & $849(4.4)$ \\
\hline The telephone number was not reachable & $805(4.2)$ \\
\hline The participant requested to be called at another time & $370(1.9)$ \\
\hline The participant unable to come due to being outside the recruitment area temporarily & $261(1.3)$ \\
\hline Other reasons & $148(0.8)$ \\
\hline Language barrier & $109(0.6)$ \\
\hline The participant unable to come due to logistics problems * & $107(0.6)$ \\
\hline The participant requested to change to another follow-up location (i.e., not at the main center) & $73(0.4)$ \\
\hline The telephone call line was not clear & $28(0.1)$ \\
\hline Unsuccessful appointment call: & $2992(15.4)$ \\
\hline $\begin{array}{l}\text { Withdrawal to participate in the study-reason: underwent treatment at another government or private } \\
\text { health center }\end{array}$ & $1363(7.0)$ \\
\hline Withdrawal to participate in the study—reason: no longer interested in the TMC project & $991(5.1)$ \\
\hline The participant moved out to distant places from any TMC recruitment centers & $332(1.7)$ \\
\hline Withdrawal to participate in the study—without giving any reason & $209(1.1)$ \\
\hline The telephone number was not available in the database & $59(0.3)$ \\
\hline The participant was deceased & $19(0.1)$ \\
\hline Withdrawal to participate in the study-reason: disappointed with the TMC project & $19(0.1)$ \\
\hline
\end{tabular}

* Denotes potential for home recruitment follow-up.

The majority of the participants fell into the category that they needed to be contacted again $(78.3 \%)$. The most frequent reasons for this category were unanswered telephone calls $(23.1 \%)$ and those that could not make up their minds or uncertain about coming for follow-up (22.6\%) (Table 1). Other reasons were related to participants' commitments $(4.4 \%)$, transportation problems $(0.6 \%)$, issues with telephone numbers or calls $(24.3 \%)$, and several other reasons that are listed in Table 1 (3.3\%). Out of this $78.3 \%, 27.6 \%$ (5331) of participants in this category were suitable for home follow-up. They were those who were uncertain, busy, or with transportation problems. In addition, 2183 participants (34.2\%) were selected based on their postcode areas and were asked whether they would agree to a home followup. A total of 86 participants agreed to come to the main center for follow-up while another 239 participants agreed to the home follow-up ( $10.9 \%$ of the 2183 selected participants). The new method of home follow-up successfully attracted participants to join the follow-up within the three months, although it only slightly improved the overall follow-up rate from $42.7 \%$ to $43.5 \%$. Participants' characteristics, such as gender, ethnicity, age, education level, employment status, and morbidity status, were significantly associated with the appointment call status, which fell into two categories: Ref. [1] successful appointment call, need to re-contact for an appointment, and [2] unsuccessful appointment call (Table 2). The characteristic for the latter was female $(60.5 \%)$, Chinese (55\%), aged $50-59$ years old $(38.2 \%)$, had a secondary education level $(51.9 \%)$, unemployed $(64.2 \%)$, obese $(85.3 \%)$, and diabetic (82.8\%) (Table 2). 
Table 2. Baseline characteristics of TMC participants residing in the Kuala Lumpur and Selangor area according to appointment call scheme 2019. $(\mathrm{N}=18,729)$.

\begin{tabular}{|c|c|c|c|c|c|c|}
\hline \multicolumn{2}{|c|}{ Baseline Characteristics } & \multirow{2}{*}{$\begin{array}{c}\begin{array}{c}\text { Successful } \\
\text { Appointment Call } \\
(\mathrm{N}=1196)\end{array} \\
\mathrm{N}(\%)\end{array}$} & \multirow{2}{*}{$\begin{array}{c}\text { Need to } \\
\text { Re-contact for } \\
\text { Appointment } \\
(\mathrm{N}=14,620) \\
\mathrm{N}(\%)\end{array}$} & \multirow{2}{*}{$\begin{array}{c}\begin{array}{c}\text { Unsuccessful } \\
\text { Appointment Call } \\
(\mathrm{N}=2913)\end{array} \\
\mathrm{N}(\%)\end{array}$} & \multirow{2}{*}{$\begin{array}{c}\text { Total } \\
\text { Participants } \\
(\mathrm{N}=18,729)\end{array}$} & \multirow[t]{2}{*}{$p$-Value } \\
\hline & & & & & & \\
\hline \multirow{2}{*}{ Gender } & Male & $516(43.1)$ & $5701(39.0)$ & 1190 (40.9) & 7407 (39.5) & \multirow{2}{*}{$0.005^{*}$} \\
\hline & Female & $680(56.9)$ & 8919 (61.0) & 1723 (59.1) & $11,322(60.5)$ & \\
\hline \multirow{4}{*}{ Race } & M'alay & $326(27.3)$ & $4272(29.2)$ & $672(23.1)$ & $5270(28.2)$ & \multirow{4}{*}{$<0.001 *$} \\
\hline & Chinese & 597 (49.9) & 7798 (53.3) & $1914(65.7)$ & $10,309(55.0)$ & \\
\hline & Indian & $253(21.2)$ & 2367 (16.2) & $300(10.3)$ & $2920(15.6)$ & \\
\hline & Others & $20(1.7)$ & $183(1.3)$ & $27(0.9)$ & $230(1.2)$ & \\
\hline \multirow{4}{*}{ Age } & $<40$ & 152 (12.7) & 1698 (11.6) & $242(8.3)$ & $2092(11.2)$ & \multirow{4}{*}{0.001 * } \\
\hline & $40-49$ & $518(43.3)$ & $6167(42.2)$ & $1107(38.0)$ & 7792 (41.6) & \\
\hline & $50-59$ & 415 (34.7) & 5129 (35.1) & $1112(38.2)$ & 6656 (35.5) & \\
\hline & $>60$ & $111(9.3)$ & $1626(11.1)$ & $452(15.5)$ & 2189 (11.7) & \\
\hline \multirow{3}{*}{ Educational Level } & Primary & $244(20.4)$ & 3865 (26.4) & $760(26.1)$ & $4869(26.0)$ & \multirow{3}{*}{$<0.001$ * } \\
\hline & Secondary & 665 (55.6) & 7641 (52.3) & 1512 (51.9) & $9818(52.4)$ & \\
\hline & Tertiary & $287(24.0)$ & 3114 (21.3) & $641(22.0)$ & 4042 (21.6) & \\
\hline \multirow{2}{*}{ Employment status } & Employed & 335 (28.0) & 4946 (33.8) & 1043 (35.8) & $6324(33.8)$ & \multirow[b]{2}{*}{$<0.001$ * } \\
\hline & Unemployed & $861(72.0)$ & $9674(66.2)$ & $1870(64.2)$ & $12,405(66.2)$ & \\
\hline \multirow{2}{*}{ Diabetes } & No & $184(15.4)$ & $2208(15.1)$ & 500 (17.2) & $2892(15.4)$ & \multirow{2}{*}{$0.019 *$} \\
\hline & Yes & $1012(84.6)$ & $12,412(84.9)$ & $2413(82.8)$ & $15,837(84.6)$ & \\
\hline \multirow{2}{*}{ Hypertension } & No & $504(42.1)$ & 6507 (44.5) & 1512 (51.9) & 8523 (45.5) & \multirow{2}{*}{$<0.001 *$} \\
\hline & Yes & $692(57.9)$ & $8113(55.5)$ & $1401(48.1)$ & $10,206(54.5)$ & \\
\hline \multirow{2}{*}{ Hypercholesterolemia } & No & $835(69.8)$ & $10,471(71.6)$ & 2183 (74.9) & $13,489(72.0)$ & \multirow{2}{*}{$<0.001 *$} \\
\hline & Yes & $361(30.2)$ & $4149(28.4)$ & $730(25.1)$ & $5240(28.0)$ & \\
\hline \multirow{2}{*}{ Obesity } & No & 209 (17.5) & $2396(16.4)$ & $428(14.7)$ & 3033 (16.2) & \multirow{2}{*}{$0.035^{*}$} \\
\hline & Yes & 987 (82.5) & $12,224(83.6)$ & $2485(85.3)$ & $15,696(83.8)$ & \\
\hline
\end{tabular}

* Denotes a significant $p$-value at 0.05 .

In the crude analysis, participants who were Chinese, above 40 years of age, had a secondary level education, were unemployed, and suffering from hypertension, hypercholesterolemia, and obesity were significantly associated with unsuccessful appointment calls ( $p$-value $<0.05$ for all) (Table 3). However, in the final model, after adjustment for other risk factors, participants who were above 50 years old were more inclined to attrition $(\mathrm{OR}=1.38(95 \% \mathrm{CI}=1.08-1.77) ; \mathrm{OR}=1.78(95 \% \mathrm{CI}=1.30-2.45))$ compared to younger participants, while the Chinese had the highest tendency to attrition with an odds ratio of 2.50 (95\% CI $=1.38-4.51$ ) compared to other ethnic groups (Table 3). The odds of an unsuccessful call for follow-up were higher among participants who were unemployed compared to employed participants ( $\mathrm{OR}=1.20 ; 95 \% \mathrm{CI}=1.02-1.41)$. Comorbidities, such as hypertension $(\mathrm{OR}=1.37,95 \% \mathrm{CI}=1.18-1.59)$ and hypercholesterolemia $(\mathrm{OR}=1.19$, $95 \% \mathrm{CI}=1.02-1.39)$, were also associated with the unsuccessful appointment call. 
Table 3. Risk factors associated with attrition (unsuccessful) in TMC participants residing in the Kuala Lumpur and Selangor area, Malaysia, March through May 2019.

\begin{tabular}{|c|c|c|c|c|c|}
\hline $\begin{array}{c}\text { Baseline } \\
\text { Characteristics }\end{array}$ & $\begin{array}{c}\text { Unsuccessful } \\
\text { Appointment Call }\end{array}$ & $\begin{array}{c}\text { Crude Odds Ratio } \\
\text { (95\% CI) }\end{array}$ & $p$-Value & $\begin{array}{c}\text { Adjusted Odds Ratio } \\
(95 \% \text { CI })\end{array}$ & $p$-Value \\
\hline Gender & $\begin{array}{c}\text { Male } \\
\text { Female }\end{array}$ & $\begin{array}{c}1 \\
1.10(0.96-1.26)\end{array}$ & 0.176 & - & \\
\hline Race & $\begin{array}{l}\text { Others } \\
\text { Malay } \\
\text { Chinese } \\
\text { Indian }\end{array}$ & $\begin{array}{c}1 \\
1.53(0.84-2.76) \\
2.37(1.32-4.26) \\
0.88(0.48-1.60)\end{array}$ & $\begin{array}{c}0.162 \\
0.004 * \\
0.673\end{array}$ & $\begin{array}{c}1 \\
1.66(0.91-3.02) \\
2.50(1.38-4.51) \\
0.91(0.50-1.67)\end{array}$ & $\begin{array}{c}0.098 \\
0.002 \text { * } \\
0.760\end{array}$ \\
\hline Age & $\begin{array}{c}<40 \\
40-49 \\
50-59 \\
>60\end{array}$ & $\begin{array}{c}1 \\
1.34(1.07-1.69) \\
1.68(1.33-2.12) \\
2.56(1.91-3.42)\end{array}$ & $\begin{array}{l}0.011 * \\
<0.001 * \\
<0.001 *\end{array}$ & $\begin{array}{c}1 \\
1.23(0.97-1.55) \\
1.38(1.08-1.77) \\
1.78(1.30-2.45)\end{array}$ & $\begin{array}{c}0.088 \\
0.009 * \\
<0.001 *\end{array}$ \\
\hline Educational Level & $\begin{array}{l}\text { Primary } \\
\text { Secondary } \\
\text { Tertiary }\end{array}$ & $\begin{array}{c}1 \\
0.73(0.62-0.87) \\
0.72(0.59-0.88)\end{array}$ & $\begin{array}{c}0.001 * \\
0.833\end{array}$ & - & \\
\hline Working status & $\begin{array}{c}\text { Employed } \\
\text { Unemployed }\end{array}$ & $\begin{array}{c}1 \\
1.43(1.24-1.66) \\
\end{array}$ & $<0.001$ * & $\begin{array}{c}1 \\
1.20(1.02-1.41)\end{array}$ & $0.026^{*}$ \\
\hline Diabetes & $\begin{array}{l}\text { No } \\
\text { Yes }\end{array}$ & $\begin{array}{c}1 \\
1.14(0.95-1.37)\end{array}$ & 0.164 & - & \\
\hline Hypertension & $\begin{array}{l}\text { No } \\
\text { Yes }\end{array}$ & $\begin{array}{c}1 \\
1.48(1.29-1.70)\end{array}$ & $<0.001$ * & $\begin{array}{c}1 \\
1.37(1.18-1.59) \\
\end{array}$ & $<0.001$ * \\
\hline Hypercholesterolemia & $\begin{array}{l}\text { No } \\
\text { Yes }\end{array}$ & $\begin{array}{c}1 \\
1.29(1.11-1.50) \\
\end{array}$ & $0.001 *$ & $\begin{array}{c}1 \\
1.19(1.02-1.39)\end{array}$ & $0.030^{*}$ \\
\hline Obesity & $\begin{array}{l}\text { No } \\
\text { Yes }\end{array}$ & $\begin{array}{c}1 \\
0.81(0.68-0.97)\end{array}$ & $0.025 *$ & - & \\
\hline
\end{tabular}

${ }^{*}$ Denotes a significant $p$-value at 0.05 .

\section{Discussion}

In this current study, our objective is to identify the cause of attrition among TMC participants and the measures to curb it. It is interesting to note that the most common withdrawal reasons based on this study were that the participants had already undergone medical treatment at another government or private healthcare center and the loss of interest to continue as a participant. Many of them were diagnosed with diabetes, hypertension, or hypercholesterolemia from the health assessment during the baseline recruitment and later underwent treatment at a government or private healthcare center. As the public healthcare service in Malaysia is still very subsidized under the government, the participants have easy access to treatment and follow-up services as patients $[25,26]$. For those who can afford or are covered by the employer's healthcare benefits or their private healthcare insurance, the private healthcare center would be more convenient $[25,27]$, thus leading to the attrition from our study. The participants might feel that they were already on a regular follow-up schedule for their illnesses, hence causing the loss of interest to further participate in the study. This was consistent with our findings that those not interested in joining a follow-up have comorbidities (87.5\% out of 2913 participants). The other explanation could be that, during the baseline recruitment, the participants might have joined the study out of curiosity and incentives (such as the free health screening provided), which might have introduced the "expected utility" effect. Once this effect had worn off, the "expected utility" of joining the study would be overwhelmed by the effect of "expected cost" of follow-up (e.g., time and energy) [28], hence making the participants lose interest.

The significant factors contributing to the attrition rate in this study were Chinese ethnicity, above 50 years old, unemployed, and having comorbidities, such as hypertension 
and hypercholesterolemia. The withdrawal rate among Chinese people was higher than other ethnicities, such as Malay and Indian, which might be due to language barriers [29]. Various methods were implemented to solve this problem, such as providing questionnaires in several languages, such as English, Mandarin, and Tamil [23], to facilitate the participants' understanding and using translator services to assist the participants during the follow-up recruitment and appointment call.

Our particular concern was those diagnosed with comorbidities at the baseline recruitment, which put them at a higher risk of developing complications in the future, yet were not interested in joining a follow-up. Another reason for this might be related to our results that most of the participants who were unable to be followed up with were unemployed and elderly, consistent with other studies [14,30-33]. It is a part of Asian culture that the children or the caregiver would take care of the elderly. This might lead to dependency on their children or caregivers, preventing them from going to the healthcare centers by themselves due to the increased frailty and transportation problems [12]. The elderly population in Malaysia is likely to be unemployed due to compulsory retirement, lack of skills, and health reasons $[34,35]$. Although there were some successful examples of the elderly cohort retention, the study was smaller $(\mathrm{N}=693)$ and limited only to a defined rural area. To combat the attrition due to transportation limitations, we introduced the home follow-up as a possible solution.

During a short span of three months, the home follow-up was three times more successful $(10.9 \%$ versus $3.9 \%)$ to attract follow-up compared to the conventional recruitment in which the participants were required to come to the main center. The overall follow-up rate increased by $0.8 \%$ (from $42.7 \%$ to $43.5 \%$ ) after the home follow-up. If this applied to all of the 5331 potential participants (who agreed to home follow-up), it was projected that the follow-up rate would be improved to $44.9 \%$. Although the improved percentage was still below the $50 \%$ cutoff point of an adequate follow-up rate as defined [4], the follow-up rate of more than $40 \%$ was still very acceptable [11].

This study has some limitations, including the fact that the contributing factors of attrition were inferred based on the baseline data. We do not know about the change of the participant's information across the time, similar to those described previously [36]. In addition, this study only focused on the participants residing in Kuala Lumpur and Selangor, and does not represent the whole cohort study. Another limitation is that this study does not assess other important attrition risks, such as cognitive function and neuropsychological tasks.

\section{Conclusions}

Those who were Chinese, aged 50 years and above, unemployed, and had comorbidities during the baseline recruitment were more inclined towards an unsuccessful follow-up. The home follow-up approach is a useful solution, but will require some key resources, such as staff and travel time. Further investigation on the cost effectiveness, feasibility, and feedback from the participants would be needed before implementing it for a longer period.

Author Contributions: Conceptualization, N.A. and R.J.; Data curation, R.O., A.D., N.A.J., N.A.M.Y., S.A.K. and N.H.B.; Formal analysis, R.O.; Funding acquisition, R.J.; Methodology, N.A.; Project administration, M.A.K.; Writing-original draft, N.A.; Writing-review \& editing, N.A., M.A.K., Y.-X.G. and R.J. All authors have read and agreed to the published version of the manuscript.

Funding: This research was funded by a top-down grant from the Ministry of Education Malaysia, grant number PDE48. Additional funding, including infrastructure and utilities, was provided by Universiti Kebangsaan Malaysia.

Institutional Review Board Statement: This study was conducted according to the guidelines laid down in the Declaration of Helsinki. All procedures involving research study participants were approved by the ethics committee of Universiti Kebangsaan Malaysia (Project Code: FF-205-2007).

Informed Consent Statement: Informed consent was obtained from all subjects involved in the study. 
Data Availability Statement: The datasets used and analyzed during the current study are available from the corresponding author on reasonable request.

Acknowledgments: The authors would like to thank all of the Malaysian Cohort staff members and research assistants. The authors would also like to thank all the community leaders and the officers from the local authorities involved who have assisted the project during the recruitment processes. The voluntary participation of all participants is greatly appreciated.

Conflicts of Interest: The funders had no role in the study's design, in the collection, analyses, or interpretation of data, in the writing of the manuscript, or in the decision to publish the results.

\section{References}

1. Seubsman, S.; Kelly, M.; Sleigh, A.; Peungson, J.; Chokkanapitak, J.; Vilainerun, D. Methods used for successful follow-up in a large scale national cohort study in Thailand. BMC Res. Notes 2011, 4, 166. [CrossRef]

2. Ward, H.; Toledano, M.B.; Shaddick, G.; Davies, B.; Elliott, P. Oxford Handbook of Epidemiology for Clinicians; Oxford University Press: Oxford, UK, 2012; ISBN 9780198529880.

3. Toledano, M.B.; Smith, R.B.; Brook, J.P.; Douglass, M.; Elliott, P. How to Establish and Follow up a Large Prospective Cohort Study in the 21st Century-Lessons from UK COSMOS. PLOS ONE 2015, 10, e0131521. [CrossRef] [PubMed]

4. Babbie, E.R. Survey Research Methods; Wadsworth: Belmont, CA, USA, 1973.

5. Greenland, S. Response and follow-up bias in cohort studies. Am. J. Epidemiol. 1977, 106, 184-187. [CrossRef]

6. Kleinbaum, D.G.; Morgenstern, H.; Kupper, L.L. Selection bias in epidemiologic studies. Am. J. Epidemiol. 1981, $113,452-463$. [CrossRef]

7. Hollen, P.J.; Gralla, R.J.; Cox, C.; Eberly, S.W.; Kris, M.G. A dilemma in analysis: Issues in the serial measurement of quality of life in patients with advanced lung cancer. Lung Cancer 1997, 18, 119-136. [CrossRef]

8. Butler, C.W.; Snyder, M.; Wood, D.E.; Curtis, J.R.; Albert, R.K.; Benditt, J.O. Underestimation of Mortality Following Lung Volume Reduction Surgery Resulting From Incomplete Follow-up. Chest 2001, 119, 1056-1060. [CrossRef] [PubMed]

9. Deeg, D. Attrition in longitudinal population studies: Does it affect the generalizability of the findings?1An introduction to the series. J. Clin. Epidemiol. 2002, 55, 213-215. [CrossRef]

10. Little, R.J.A.; Rubin, D.B. Statistical Analysis with Missing Data, 2nd ed.; John Wiley \& Sons, Inc.: Hoboken, NJ, USA, 2019; ISBN 0-471-18386-5.

11. Kristman, V.; Manno, M.; Côté, P. Loss to Follow-Up in Cohort Studies: How Much is Too Much? Eur. J. Epidemiol. 2003, 19, 751-760. [CrossRef]

12. McLean, R.R.; Hannan, M.T.; Epstein, B.E.; Bouxsein, M.L.; Cupples, L.A.; Murabito, J.; Kiel, D.P. Elderly Cohort Study Subjects Unable to Return for Follow-up Have Lower Bone Mass than Those Who Can Return. Am. J. Epidemiol. 2000, 151, 689-692. [CrossRef]

13. Bisgard, K.M.; Folsom, A.R.; Hong, C.-P.; Sellers, T.A. Mortality and Cancer Rates in Nonrespondents to a Prospective Study of Older Women: 5-Year Follow-up. Am. J. Epidemiol. 1994, 139, 990-1000. [CrossRef]

14. Chatfield, M.D.; Brayne, C.E.; Matthews, F.E. A systematic literature review of attrition between waves in longitudinal studies in the elderly shows a consistent pattern of dropout between differing studies. J. Clin. Epidemiol. 2005, 58, 13-19. [CrossRef]

15. Matthews, F.E.; Chatfield, M.; Brayne, C. An investigation of whether factors associated with short-term attrition change or persist over ten years: Data from the Medical Research Council Cognitive Function and Ageing Study (MRC CFAS). BMC Public Health 2006, 6, 185. [CrossRef]

16. Stange, J.P.; Connolly, S.L.; Burke, T.A.; Hamilton, J.L.; Hamlat, E.J.; Abramson, L.Y.; Alloy, L.B. Inflexible Cognition Predicts First Onset of Major Depressive Episodes in Adolescence. Depress. Anxiety 2016, 33, 1005-1012. [CrossRef] [PubMed]

17. Stange, J.P.; Jenkins, L.M.; Bessette, K.L.; Kling, L.R.; Bark, J.S.; Shepard, R.; Hamlat, E.J.; DelDonno, S.; Phan, K.L.; Passarotti, A.M.; et al. Predictors of Attrition in Longitudinal Neuroimaging Research: Inhibitory Control, Head Movement, and Resting-State Functional Connectivity. Brain Connect. 2018, 8, 527-536. [CrossRef]

18. Gustavson, K.; von Soest, T.; Karevold, E.; Røysamb, E. Attrition and generalizability in longitudinal studies: Findings from a 15-year population-based study and a Monte Carlo simulation study. BMC Public Health 2012, 12, 918. [CrossRef] [PubMed]

19. Lamers, F.; Hoogendoorn, A.W.; Smit, J.H.; van Dyck, R.; Zitman, F.G.; Nolen, W.A.; Penninx, B.W. Sociodemographic and psychiatric determinants of attrition in the Netherlands Study of Depression and Anxiety (NESDA). Compr. Psychiatry 2012, 53, 63-70. [CrossRef] [PubMed]

20. Lewis, G.; Jones, P.B.; Goodyer, I.M. The ROOTS study: A 10-year review of findings on adolescent depression, and recommendations for future longitudinal research. Soc. Psychiatry Psychiatr. Epidemiol. 2016, 51, 161-170. [CrossRef]

21. Glymour, M.M.; Chene, G.; Tzourio, C.; Dufouil, C. Brain MRI markers and dropout in a longitudinal study of cognitive aging: The Three-City Dijon Study. Neurology 2012, 79, 1340-1348. [CrossRef]

22. Dawson, E.L.; Caveney, A.F.; Meyers, K.K.; Weisenbach, S.L.; Giordani, B.; Avery, E.T.; Schallmo, M.-P.; Bahadori, A.; Bieliauskas, L.A.; Mordhorst, M.; et al. Executive Functioning at Baseline Prospectively Predicts Depression Treatment Response. Prim. Care Companion CNS Disord. 2017, 19. [CrossRef] 
23. Jamal, R.; Syed Zakaria, S.Z.; Kamaruddin, M.A.; Abd Jalal, N.; Ismail, N.; Mohd Kamil, N.; Abdullah, N.; Baharudin, N.; Hussin, N.H.; Othman, H.; et al. Cohort Profile: The Malaysian Cohort (TMC) project: A prospective study of non-communicable diseases in a multi-ethnic population. Int. J. Epidemiol. 2015, 44, 423-431. [CrossRef]

24. Edwards, P.J.; Roberts, I.; Clarke, M.J.; DiGuiseppi, C.; Wentz, R.; Kwan, I.; Cooper, R.; Felix, L.M.; Pratap, S. Methods to increase response to postal and electronic questionnaires. Cochrane Database Syst. Rev. 2009. [CrossRef]

25. Chee, H.L. Ownership, control, and contention: Challenges for the future of healthcare in Malaysia. Soc. Sci. Med. 2008, 66, 2145-2156. [CrossRef]

26. Chongsuvivatwong, V.; Phua, K.H.; Yap, M.T.; Pocock, N.S.; Hashim, J.H.; Chhem, R.; Wilopo, S.A.; Lopez, A.D. Health and healthcare systems in southeast Asia: Diversity and transitions. Lancet 2011, 377, 429-437. [CrossRef]

27. Pocock, N.S.; Phua, K.H. Medical tourism and policy implications for health systems: A conceptual framework from a comparative study of Thailand, Singapore and Malaysia. Global. Health 2011, 7, 12. [CrossRef] [PubMed]

28. Anand, P. Foundations of Rational Choice under Risk; Oxford University Press: Oxford, UK, 1995; ISBN 9780198774426.

29. Center of Disease Control. Behavioral Risk Factor Surveillance System (BRFSS) Summary Data Quality Report; CDC: Atlanta, GA, USA, 2000.

30. Costello, H.; Hayes, G.M.; Francis, P.T. Factors affecting withdrawal and donation attrition in the brains for dementia research cohort. Int. J. Geriatr. Psychiatry 2018, 33, 1709-1716. [CrossRef] [PubMed]

31. Garcia, M.; Fernandez, E.; Schiaffino, A.; Borrell, C.; Marti, M.; Borras, J.M. Attrition in a population-based cohort eight years after baseline interview: The Cornella Health Interview Survey Follow-up (CHIS.FU) Study. Ann. Epidemiol. 2005, 15, 98-104. [CrossRef] [PubMed]

32. Michelet, M.; Lund, A.; Sveen, U. Strategies to recruit and retain older adults in intervention studies: A quantitative comparative study. Arch. Gerontol. Geriatr. 2014, 59, 25-31. [CrossRef]

33. Vega, S.; Benito-León, J.; Bermejo-Pareja, F.; Medrano, M.J.; Vega-Valderrama, L.M.; Rodríguez, C.; Louis, E.D. Several factors influenced attrition in a population-based elderly cohort: Neurological disorders in Central Spain Study. J. Clin. Epidemiol. 2010, 63, 215-222. [CrossRef]

34. Mohd, S.; Senadjki, A.; Mansor, N. Trend of Poverty among Elderly: Evidence from Household Income Surveys Trend of Poverty among Elderly: Evidence from Household. J. Poverty 2018, 22, 89-107. [CrossRef]

35. Benjamin, C.; Paim, L.; Masud, J.; Tengku Abdul Hamid, T. The future of the Malaysian older employees: An exploratory study. Int. J. Bus. Manag. 2010, 5, 125-132. [CrossRef]

36. Del Brutto, O.H.; Castillo, P.R.; Sedler, M.J.; Del Brutto, V.J.; Zambrano, M.; Mera, R.M.; Wright, C.B.; Rundek, T. Reasons for Declining Consent in a Population-Based Cohort Study Conducted in a Rural South American Community. J. Environ. Public Health 2018, 2018, 1-7. [CrossRef] [PubMed] 